JMB

\title{
Stabilization of GroEL Minichaperones by Core and Surface Mutations
}

\section{Qinghua Wang, Ashley M. Buckle and Alan R. Fersht ${ }^{\star}$}

Cambridge Centre for Protein Engineering and Cambridge University Chemical Laboratory, MRC Centre, Hills Road, Cambridge, CB2 2QH United Kingdom

\begin{abstract}
We report the crystal structures of two hexa-substituted mutants of a GroEL minichaperone that are more stable than wild-type by 7.0 and $6.1 \mathrm{kcal} \mathrm{mol}^{-1}$. Their structures imply that the increased stability results from multiple factors including improved hydrophobic packing, optimised hydrogen bonding and favourable structural rearrangements. It is commonly believed that protein core residues are immutable and generally optimized for energy, while on the contrary, surface residues are variable and hence unimportant for stability. But, it is now becoming clear that mutations of both core and surface residues can increase protein stability, and that protein cores are more flexible and thus more tolerant to mutation than expected. Sequence comparison of homologous proteins has provided a way to pinpoint the residues that contribute constructively to stability and to guide the engineering of protein stability. Stabilizing mutations identified by this approach are most frequently located at protein surfaces but with a few found in protein cores. In the latter case, local flexibility in the hydrophobic core is the key factor that allows the energetically favourable burial of larger hydrophobic sidechains without undue energetic penalties from steric clashes.
\end{abstract}

(C) 2000 Academic Press

Keywords: flexibility; GroEL minichaperone; protein stability; sequence homology; stabilization

\section{Introduction}

Understanding the forces that govern protein stability and engineering proteins with enhanced stability are two major goals of protein engineering. The contributions of different interactions to protein stability have been extensively investigated in several model systems, such as barnase (Fersht \& Serrano, 1993), T4 lysozyme (Matthews, 1995) and gene $\mathrm{V}$ protein (Terwilliger, 1995). This is usually done by deleting the moieties of sidechains that are involved in the interactions under question and measuring the resulting changes in

The structural data and the atomic coordinates will be deposited in RCSB Protein Data Bank. The coordinates are now available from the authors at

wang@crystal.harvard.edu or ab@mrc-lmb.cam.ac.uk

Present address: Q. Wang, Dept. of Molecular \& Cellular Biology, Howard Hughes Medical Institute, Harvard University, 7 Divinity Ave, Cambridge, MA 02138, USA.

Abbreviations used: Cpn60, chaperonin 60; rmsd, root-mean-square deviation.

E-mail address of the corresponding author: arf10@cam.ac.uk stability (Fersht, 1999). However, the reverse process, engineering increased stability by introducing new interactions, has proven to be more difficult. Since the existing interactions in a protein are generally finely tuned and interdependent, the introduction of one interaction may lead to unexpected perturbations in protein structure, which may offset the stabilizing effect of the introduced interactions to various extents and, most frequently, result in destabilization. The current obstacle of engineering protein stability is to identify the sites within a protein that will lead to stabilization upon mutation (Sandberg \& Terwilliger, 1991).

There are currently several approaches employed to enhance protein stability. The rational approach to stabilization is extremely difficult, since it is not generally possible to predict the energetic and structural response to mutation in proteins, although the statistics of isolated helices and parts of sheets are predictable to varying degrees (Munoz et al., 1996; Regan et al., 1996). Some insight into protein stabilization has also been gained from the structural comparison of thermophilic proteins with their mesophilic counterparts (Russell \& Taylor, 1995). However, the difficulty underlying this approach is that the sequence 
divergence between these proteins is prohibitively too large to quantitate the contribution to protein stability on the basis of individual residues. Alternatively, an empirical approach of exploring naturally occurring variations among a family of homologous proteins has proven to be very powerful in picking up stabilizing mutations that would have been missed by structural analysis (Wang et al., 1999). The combination of several stabilizing mutations yields superstable variants (Serrano et al., 1993; Nikolova et al., 1998; Wang et al., 1999), which are valuable resources that offer an opportunity for understanding the stabilizing effect of individual mutations by detailed structural studies.

Here we report the $2.2 \AA$ resolution crystal structures of two superstable minichaperones, GroEL(191-376) M1 and M2. Each mutant contains six mutations, five of which, Ala212 $\rightarrow$ Glu, Met233 $\rightarrow$ Leu, Ile305 $\rightarrow$ Leu, Glu308 $\rightarrow$ Lys and Asn326 $\rightarrow$ Thr, are shared by M1 and M2, whilst the sixth is Ala223 $\rightarrow$ Thr in M1 and Ala223 $\rightarrow$ Val in M2. Their locations within the protein vary: Ala223 and Met233 are completely buried in the hydrophobic core, whereas Ala212, Ile305, Glu308 and Asn326, which have greater than $5 \%$ of surface area exposed to solvent, are regarded as protein surface residues (Miller et al., 1987). The structural basis for the observed stabilizing effects of the mutations is discussed.

\section{Results and Discussion}

Crystals of GroEL(191-376) M1 and M2 grew in the space group $P 22_{1} 2{ }_{1}$, non-isomorphous to the wild-type crystals $\left(P 22_{1} 2_{1} 2_{1}\right)$. There is one molecule in the asymmetric unit. Details of data collection and model refinement are summarized in Table 1. Overall, the refined models fit the electron density very well. The density at the sites of mutation is very well defined and unambiguous, the only exception is the side-chain of Lys308 that cannot be completely resolved, possibly due to the intrinsic mobility of the loop to which it belongs. Both refined structures contain 186 protein residues and seven additional residues from the N-terminal histidine-tag as observed in wild-type (Buckle et al., 1997). A glycerol molecule, involved in multiple hydrogen bonds to surface residues, has also been built into the electron density. The average temperature factors for main-chain and side-chain atoms are 17.0 and $19.3 \AA^{2}$ for M1, 31.4 and $34.1 \AA^{2}$ for M2, respectively. The overall temperature factor of M2 is higher compared with M1.

The overall structures of M1 and M2 are very similar to the wild-type structure. The superposition of backbones of M1 and M2 on the wild-type backbone gives an average root-mean-square deviation (rmsd) of $0.39 \AA$ and $0.38 \AA$ for all the mainchain atoms of M1 and M2, respectively. The deviations for side-chain atoms are somewhat larger, $0.78 \AA$ for M1 and $0.71 \AA$ for M2. However, significant changes are observed in several regions,
Table 1. X-ray data collection and refinement statistics

GroEL(191-376) M1 GroEL(191-376) M2

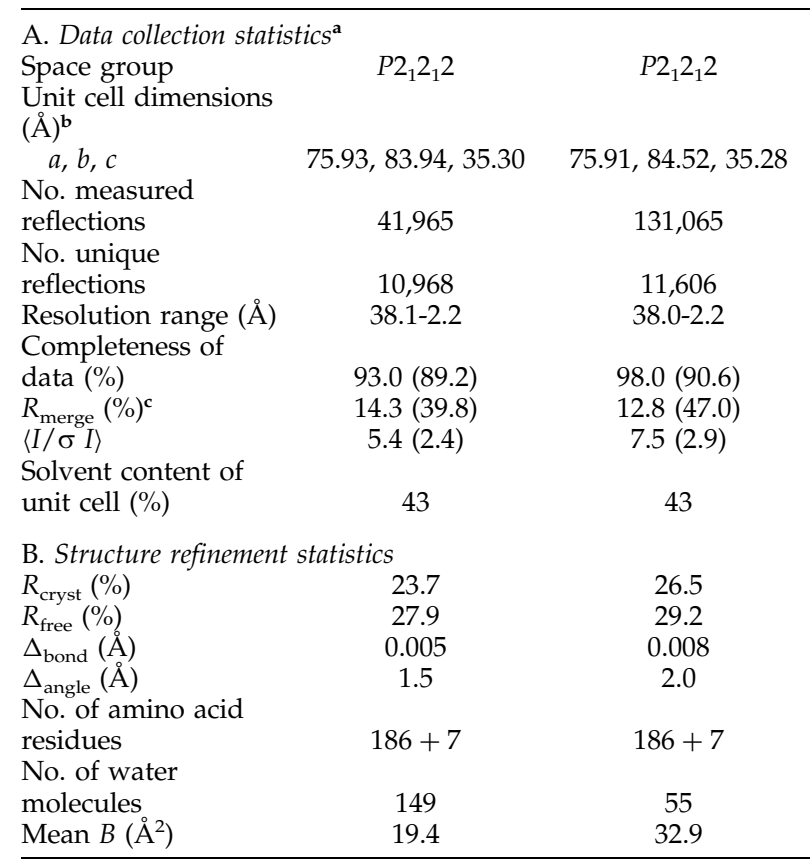

${ }^{a}$ Values in parentheses are for the highest resolution shell.

b The unit cell dimensions of GroEL(191-376) wild-type crystals are: $a=47.72 \AA, b=63.81 \AA, c=75.10 \AA\left(P 22_{1} 2_{1} 2_{1}\right)$ (Buckle et al., 1997).

${ }^{c} R_{\text {merge }}$ gives the agreement between intensities of repeated measurements of the same reflections and is defined as $\Sigma\left(I_{h, I}-\left\langle I_{h}\right\rangle\right) / \Sigma I_{h, I}$, where $I_{h, I}$ are individual values and $\left\langle I_{h}\right\rangle$ is the mean value of the intensity of reflection $h$.

including residues 223-238? where three core mutations $\quad$ Ala223 $\rightarrow$ Thr, Ala223 $\rightarrow$ Val and Met233 $\rightarrow$ Leu are located, residues 267-270 which is at the $\mathrm{C}$ terminus of helix $\mathrm{H} 9$, and residues 302307 which is part of a highly mobile loop (residues 299-316).

The increase in stability of GroEL(193-345) M1 is almost exactly the sum of the free energy changes from all six of its constituent mutations $( \pm 0.1 \mathrm{kcal}$ $\mathrm{mol}^{-1}$ ), while the additivity in GroEL(193-345) M2 is nearly so $\left( \pm 0.4 \mathrm{kcal} \mathrm{mol}^{-1}\right)$. We can assume that the structural responses of individual mutations are additive in M1 and approximately additive in M2, which simplifies the analysis.

The structural response to each substitution is highly variable. A detailed description of the structural changes caused by the mutations and the rationalization of the mutational effects on protein stability are summarized in Table 2.

\section{Mutations in the protein hydrophobic core}

The small-to-large mutations Ala223 $\rightarrow$ Thr and Ala223 $\rightarrow$ Val are located in the hydrophobic core. Ala223 $\rightarrow$ Thr causes large local structural changes, while Ala223 $\rightarrow$ Val results in the smallest structural changes of all the mutations (Table 2). The greater stability of Ala223 $\rightarrow$ Thr compared to the 
more hydrophobic substitution Ala223 $\rightarrow$ Val was not anticipated, and most likely results from the movements of the main-chain and side-chain of Thr223 that bring the OG1 atom of Thr223 closer to its hydrogen bonding partners (Figure 1(a)). It is surprising that the hydrophobic core of this protein accommodates a larger side-chain without strain or steric clash, in contrast to many destabilizations caused by small-to-large mutations in protein cores (Karpusas et al., 1989; Daopin et al., 1991). The side-chain of Thr223 in M1 adopts a conformation distinct to that of Val223 in M2 (Figure 1(b)), indicating local flexibility.

Met233 $\rightarrow$ Leu causes very large local structural changes in M1 and to a lesser extent in M2 (Table 2). Structural shifts are propagated through $\alpha$-helix H8 (residues 228-243). The side-chain of Leu309 in M1 is forced to move backwards to avoid steric clash. It has been suggested that the mutation Met $\rightarrow$ Leu at entirely buried sites can stabilize a protein through an increase in sidechain hydrophobicity and the relative advantage in entropy of ordering a less flexible leucine sidechain in the folded structures (Gassner et al., 1996). In this study, Met233 $\rightarrow$ Leu is the most stabilizing of all the mutants, possibly emphasizing the effects of increased hydrophobic packing and conformational entropy.

The side-chain of Met233 displays two distinct conformations in wild-type protein (Figure 2(a)). In the mutant structures, though no alternative sidechain conformations are seen for Leu233, the conformation of Leu233 in M1 is different from that in M2 (Figure 2(b)). The difference is likely to be real, since the corresponding movement of the sidechain of Leu309 is observed to avoid steric clash. Taken together, the core structure around residue 233 displays a high degree of local flexibility. This local flexibility is further supported by the significant higher temperature factor of $\alpha$-helix H8. Moreover, the significant movements of surrounding residues in response to Ala223 $\rightarrow \mathrm{Thr}$ and Met233 $\rightarrow$ Leu, suggest that local flexibility is important in allowing the structural relaxation required for stabilization, and support that the flexibility of backbone plays an important role in repacking protein interiors (Daopin et al., 1991; Baldwin et al., 1993).

Further evidence for flexibility at positions 223 and 233 is obtained from the $1.7 \AA$ resolution crystal structure of the apical domain of a Cpn60 protein from Thermus thermophilus which has an identity of $67 \%$ in primary sequence with GroEL in the region of 193-345 (Walsh et al., 1999). The least-squares fitting of T. thermophilus Cpn60(192336) on the corresponding region of GroEL(191376) yields a deviation of $0.4 \AA$ for all main-chain atoms, comparable to those values for M1 and M2. The side-chains of Val223 and Leu233 in T. thermophilus Cpn60(192-336) are completely buried and display two distinct conformations (Figures 1(c) and $2(\mathrm{c})$ ).

\section{Mutations at the protein surface}

Ala212 is at the protein surface although most of its surface is buried by packing against adjacent residues. The mutation Ala212 $\rightarrow$ Glu causes local and small structural changes in both mutants (Table 2). Two localized water molecules are found within hydrogen bonding distance with the sidechain of Glu212 in M1 whilst none in M2 (Figure 3(a) and (b)). Hydrogen bonding and increased burial of hydrophobic area are believed to be the main contributors to the observed stabilization.

Asn326 is also at the protein surface. The mutation Asn326 $\rightarrow$ Thr causes small and localized changes in surrounding structures, with the largest movement of the backbone being Thr326. The movement of the main-chain and side-chain atoms of Thr326 most likely optimizes the hydrogen bonding geometry resulting in increased stability. There is no net increase in the number of hydrogen bonds, however (Figure 3(c) and (d)).

Ile305 and Glu308 are in a solvent-exposed segment of the mobile loop. The largest changes in both mutant structures are observed in the region 302-307 containing the mutation Ile305 $\rightarrow$ Leu, where Leu305 exposes a greater hydrophobic surface than Ile305 in the wild-type, this being energetically unfavourable. The observed large shift of the segment 302-307 is most likely the major contributor to the stabilization of this mutation. It is possible that the gain in stability as a consequence of the rearrangement of the segment 302-307 is so favourable that it occurs at the expense of exposing more hydrophobic surface to solvent. The mutation Glu308 $\rightarrow$ Lys introduces a larger and more flexible side-chain on the protein surface whose terminal atoms cannot be resolved.

In summary, the seven mutations described above can be split into three groups according to their location and the structural rearrangements they cause.

(i) Ala223 $\rightarrow$ Thr, $\quad$ Ala223 $\rightarrow$ Val and Met233 $\rightarrow$ Leu. These residues are entirely buried in the protein hydrophobic core, and substitutions cause significant structural rearrangements. Increased hydrophobic packing is the main stabilizing force. However, in the case of Ala223 $\rightarrow$ Thr, buried hydrogen bonds are responsible for the enhanced stability. Both sites display a degree of flexibility.

(ii) Ala212 $\rightarrow$ Glu and Asn326 $\rightarrow$ Thr. These are surface residues. Increased burial of hydrophobic area and optimized hydrogen bonding are the main contributors to the stabilization. Relatively small structural rearrangements are required in order to accommodate these mutations.

(iii) Ile305 $\rightarrow$ Leu and Glu308 $\rightarrow$ Lys. These are surface residues with largely exposed surfaces. Substitutions at these positions result in modest increases in protein stability and large changes in 
Table 2. Summary of the structural changes for the mutations analysed in this study

\begin{tabular}{|c|c|c|c|c|}
\hline & Ala212 $\rightarrow$ Glu & Ala223 $\rightarrow$ Thr & Ala223 $\rightarrow$ Val & Met233 $\rightarrow$ Leu \\
\hline $\begin{array}{l}\text { Description of } \\
\text { mutations }\end{array}$ & $\begin{array}{l}\text { This mutation is near the } N \\
\text { terminus of } \beta \text {-strand S7. The side- } \\
\text { chain of Ala212 is largely buried } \\
\text { with a solvent-accessible surface } \\
\text { area of } 6 \AA^{2} \text { and points toward the } \\
\text { protein surface. This mutation } \\
\text { stabilizes GroEL(193-345) by } 1.38 \\
\text { kcal mol }{ }^{-1} \text { and increases the } T_{\mathrm{m}} \text { by } \\
5.6^{\circ} \mathrm{C}\end{array}$ & \multicolumn{2}{|c|}{$\begin{array}{l}\text { Ala223 is a buried core residue at the } C \text { terminus of } \beta \text {-strand } S 8 \text { with a solvent- } \\
\text { accessible surface area of } 2 \AA^{2} \text {. The mutation Ala223 } \rightarrow \text { Thr stabilizes } \\
\text { GroEL(193-345) by } 1.55 \mathrm{kcal} \mathrm{mol}^{-1} \text { and increases the } T_{\mathrm{m}} \text { by } 5.6^{\circ} \mathrm{C} \text {, while } \\
\text { Ala223 } \rightarrow \text { Val stabilizes the protein by } 1.03 \mathrm{kcal} \mathrm{mol}^{-1} \text { and increases the } \\
T_{\mathrm{m}} \text { by } 1.5^{\circ} \mathrm{C}\end{array}$} & $\begin{array}{l}\text { This mutation is on the buried face } \\
\text { of } \alpha \text {-helix } \mathrm{H} 8 \text { with a solvent- } \\
\text { accessible surface area of } 0 \AA^{2} \text {. The } \\
\text { side-chain of Met } 233 \text { in the wild- } \\
\text { type displays two alternative } \\
\text { conformations. This mutation } \\
\text { stabilizes GroEL(193-345) by } 1.78 \\
\text { kcal mol }{ }^{-1} \text { and increases the } T_{\mathrm{m}} \text { by } \\
5.9^{\circ} \mathrm{C}\end{array}$ \\
\hline $\begin{array}{l}\text { Structural changes } \\
\text { caused by mutations }\end{array}$ & $\begin{array}{l}\text { The } C B \text { and introduced } C G \text { and } C D \\
\text { atoms of Glu212 are highly buried, } \\
\text { with the OE1 and OE } 2 \text { atoms largely } \\
\text { exposed to the solvent }\left(51 \AA^{2}\right) \text {. This } \\
\text { mutation causes small and localized } \\
\text { structural changes in both mutant } \\
\text { structures, with a deviation of } 0.3- \\
0.4 \AA \text { for main-chain atoms and } 0.5- \\
0.7 \AA \text { for side-chain atoms for all } \\
\text { residues within a radius of } 4.5 \AA\end{array}$ & $\begin{array}{l}\text { Thr223 in M1 is totally inaccessible } \\
\text { to solvent. The structural changes } \\
\text { associated with this mutation are } \\
\text { large. Its main-chain and side-chain } \\
\text { atoms move by an average of } 0.5 \AA \text {. } \\
\text { The average movement of the main- } \\
\text { chain and side-chain atoms for all } \\
\text { residues within a radius of } 4.5 \AA \text { are } \\
0.41 \AA \text { and } 0.89 \AA \text {, respectively }\end{array}$ & $\begin{array}{l}\text { Val223 in M1 is entirely inaccessible } \\
\text { to solvent. It closely resembles the } \\
\text { conformation of Ala223 in the wild- } \\
\text { type. The structural shifts caused by } \\
\text { this mutation are the smallest of all } \\
\text { the mutations. The deviation for the } \\
\text { main-chain and side-chain atoms is } \\
0.22 \text { and } 0.29 \AA \text {. Its side-chain } \\
\text { adopts the most favourable } \\
\text { conformation }(\chi 1=169) \text { with no } \\
\text { strain }\end{array}$ & $\begin{array}{l}\text { In M1, Leu233 has a solvent- } \\
\text { accessible surface area of } 1 \AA^{2} \text { and } \\
\text { causes large structural changes. The } \\
\text { main-chain atoms of Leu233 shift } \\
\text { by } 0.85 \AA \text {, the same for the } \\
\text { backbone of the first half of } H 8 \\
(228-233) \text {. The side-chains of H8 } \\
\text { (228-243) move by an average of } \\
1.3 \AA \text {. The side-chain of Leu309 } \\
\text { moves away by } 1.6 \AA \text {. In } M 2 \text {, } \\
\text { Leu233 remains entirely buried and } \\
\text { causes much smaller structural } \\
\text { changes (rmsd of } 0.37 \AA \text { for main- } \\
\text { chain atoms of Leu233) }\end{array}$ \\
\hline $\begin{array}{l}\text { Interactions } \\
\text { introduced or deleted } \\
\text { upon mutation }\end{array}$ & $\begin{array}{l}\text { In M1, the OE1 atom of Glu } 212 \\
\text { hydrogen bonds with the OG1 of } \\
\text { Thr210 ( } 3.50 \AA), \text { Wat } 23(3.63 \AA) \text { and } \\
\text { Wat107 ( } 3.96 \AA) \text {. The OE2 atom of } \\
\text { Glu212 also hydrogen bonds with } \\
\text { Wat23 ( } 3.04 \AA) \text {. In M2, the OG1 of } \\
\text { Thr210 forms two intramolecular } \\
\text { hydrogen bonds with the OE1 ( } 3.75 \\
\AA) \text { and OE2 ( } 2.90 \AA) \text { of Glu212 }\end{array}$ & $\begin{array}{l}\text { The OG1 of Thr } 223 \text { forms three } \\
\text { good hydrogen bonds with } \\
\text { surrounding atoms: NH of Asp } 224 \\
(2.96 \AA) \text { NH of Lys } 225(3.17 \AA) \text { and } \\
\text { CO of Ile } 301(2.71 \AA)\end{array}$ & $\begin{array}{l}\text { This mutation introduces two } \\
\text { methyl groups into the protein } \\
\text { hydrophobic core }\end{array}$ & $\begin{array}{l}\text { This mutation replaces a flexible } \\
\text { methionine side-chain with a } \\
\text { leucine side-chain that has a higher } \\
\text { side-chain hydrophobicity and } \\
\text { costs less in entropy when ordered } \\
\text { in folded proteins }\end{array}$ \\
\hline $\begin{array}{l}\text { Rationalization of the } \\
\text { mutational effects on } \\
\text { protein stability }\end{array}$ & $\begin{array}{l}\text { The stabilization of this mutation } \\
\text { results from hydrogen bonding and } \\
\text { increased burial of hydrophobic area } \\
\left(25 \AA^{2}\right) \text {, which more than } \\
\text { compensates for the estimated cost } \\
\text { of } 1.46 \mathrm{kcal} \mathrm{mol}^{-1} \text { in conformational } \\
\text { entropy for ordering a larger side- } \\
\text { chain in the folded protein }\end{array}$ & $\begin{array}{l}\text { Considering that the increase in } \\
\text { buried hydrophobic area relative to } \\
\text { Ala223 in the wild-type is small ( } 7 \\
\AA^{2} \text { ), the three hydrogen bonds must } \\
\text { have overcompensated for the } \\
\text { penalty of } 1.08 \mathrm{kcal}^{-1} \text { mol for } \\
\text { burying a polar group (Thr) in the } \\
\text { protein core, and results in the } \\
\text { stabilization }\end{array}$ & $\begin{array}{l}\text { The stabilization of this mutation } \\
\text { results from larger buried } \\
\text { hydrophobic area }\left(49 \AA^{2}\right) \text { relative to } \\
\text { the wild-type and an improvement } \\
\text { in interior packing }\end{array}$ & $\begin{array}{l}\text { The stabilization most likely results } \\
\text { from improved hydrophobic } \\
\text { packing and gain in conformational } \\
\text { entropy, given that the contri- } \\
\text { butions of other factors such as } \\
\text { helical propensity and changes in } \\
\text { buried hydrophobic area are } \\
\text { negligible }\end{array}$ \\
\hline General comments & $\begin{array}{l}\text { The hydrogen bonding pattern of } \\
\text { Glu212 is different in M1 and M2 }\end{array}$ & $\begin{array}{l}\text { The movement of the main-chain } \\
\text { and side-chain atoms of Thr } 223 \\
\text { optimizes the hydrogen bonding } \\
\text { interactions }\end{array}$ & $\begin{array}{l}\text { The side-chain of Val223 adopts a } \\
\text { conformation distinct to that of } \\
\text { Thr } 223 \text { in M1, indicating local } \\
\text { flexibility around site } 223\end{array}$ & $\begin{array}{l}\text { The side-chain conformations of } \\
\text { Leu } 233 \text { in M1 and M2 are different, } \\
\text { indicating local flexibility around } \\
\text { site } 233\end{array}$ \\
\hline
\end{tabular}


Table 2. (Continued)

\begin{tabular}{|c|c|c|c|}
\hline & Ile305 $\rightarrow$ Leu & Glu308 $\rightarrow$ Lys & Asn $326 \rightarrow$ Thr \\
\hline Description of mutations & \multicolumn{2}{|c|}{$\begin{array}{l}\text { Ile305 and Glu308 are located in the solvent-exposed segment of a mobile loop (residues 299-316). } \\
\text { They are largely solvent-exposed with solvent-accessible surface area of } 127 \text { and } 97 \AA^{2} \text {, respectively. } \\
\text { The region 301-308 is the least resolved in the crystal structures of intact GroEL and minichaperone } \\
\text { GroEL(191-345), suggesting inherent flexibility. The mutations Ile305 } \rightarrow \text { Leu and Glu308 } \rightarrow \text { Lys stabilize } \\
\text { GroEL(193-345) by } 0.69 \mathrm{kcal} \mathrm{mol}^{-1} \text { and } 0.34 \mathrm{kcal} \mathrm{mol}^{-1} \text {, respectively }\end{array}$} & $\begin{array}{l}\text { This mutation is the last residue of } \beta \text {-strand } \\
\text { S11 with a solvent-accessible surface area of } \\
60 \AA^{2} \text {. In the wild-type structure, the side- } \\
\text { chain of Asn } 326 \text { forms five hydrogen bonds } \\
\text { with neighbouring atoms. This mutation } \\
\text { stabilizes GroEL(193-345) by } 1.35 \mathrm{kcal} \mathrm{mol}^{-1} \\
\text { and increases the } T_{\mathrm{m}} \text { by } 6.8^{\circ} \mathrm{C}\end{array}$ \\
\hline $\begin{array}{l}\text { Structural changes caused by } \\
\text { mutations }\end{array}$ & $\begin{array}{l}\text { The largest changes in both mutant structures } \\
\text { were observed in region } 302-307 \text { containing } \\
\text { this mutation. The average shift for backbone } \\
\text { atoms in region } 302-307 \text { is } 0.95 \AA \text { in } M 1 \text { and } \\
2.16 \AA \text { in } M 2 . \text { The main-chain atoms of Leu } 305 \\
\text { move by } 0.93 \AA \text { in } M 1 \text { and } 2.79 \AA \text { in } M 2 . \\
\text { Leu } 305 \text { exposes larger hydrophobic surface } \\
\text { than Ile } 305 \text { in the wild-type, } 139 \AA^{2} \text { in } M 1 \text { and } \\
145 \AA^{2} \text { in M2 }\end{array}$ & $\begin{array}{l}\text { In both mutant structures, the terminus of the } \\
\text { side-chain of Lys } 308 \text { is not resolved, however, } \\
\text { its visible portion closely follows the } \\
\text { orientation of Glu } 308 \text { side-chain in the wild- } \\
\text { type. The main-chain atoms of Lys } 308 \text { move } \\
\text { by } 0.78 \AA \text { in } M 1 \text { and } 0.44 \AA \text { in } M 2 \text {. The } \\
\text { average main-chain movement for residues } \\
\text { within a radius of } 4.5 \AA \text { is } 0.64 \AA \text { in } M 1 \text { and } \\
0.79 \AA \text { in } M 2 \text {. The side-chain of Glu310 moves } \\
\text { inwards by } 3.4 \AA \text { in } M 1\end{array}$ & $\begin{array}{l}\text { This mutation causes small and localized } \\
\text { changes at the mutation site and surrounding } \\
\text { residues in both M1 and M2. The largest } \\
\text { movement was observed at the mutation } \\
\text { site, the rmsd is } 0.4 \AA \text { and } 1.1 \AA \text { for the } \\
\text { main-chain and side-chain atoms of Thr } 326 \text {, } \\
\text { respectively, in both structures. This } \\
\text { movement brings the hydroxyl group of } \\
\text { Thr } 326 \text { to the position of the OD1 atom of } \\
\text { Asn } 326 \text { in the wild-type }\end{array}$ \\
\hline $\begin{array}{l}\text { Interactions introduced or } \\
\text { deleted upon mutation }\end{array}$ & $\begin{array}{l}\text { Ile } 305 \text { in the wild-type and Leu } 305 \text { in the } \\
\text { mutant structures are largely solvent-exposed. } \\
\text { There are no obvious changes in interactions } \\
\text { upon mutation }\end{array}$ & & $\begin{array}{l}\text { In M1, the OG1 atom of Thr } 326 \text { makes five } \\
\text { hydrogen bonds with NH of Lys327 ( } 3.01 \AA) \text {, } \\
\text { NH of Asp328 ( } 3.22 \AA), \mathrm{NH} \text { of Thr } 329 \\
\text { ( } 2.92 \AA \text { ), OG1 of Thr } 329 \text { ( } 3.44 \AA) \text {, and CO of } \\
\text { Thr } 329 \text { ( } 3.11 \AA \text { ). The hydrogen bonds formed } \\
\text { by the hydroxyl group of Thr } 326 \text { in M1 are } \\
\text { almost identical to those observed in M2. } \\
\text { There is no net increase in the number of } \\
\text { hydrogen bonds }\end{array}$ \\
\hline $\begin{array}{l}\text { Rationalization of the } \\
\text { mutational effects on protein } \\
\text { stability }\end{array}$ & $\begin{array}{l}\text { The stabilization of this mutation is most likely } \\
\text { the consequence of the observed large shift of } \\
\text { the segment } 302-307 \text { in both mutant structures, } \\
\text { which overcompensates for the unfavourable } \\
\text { exposure of larger hydrophobic area of Leu305 } \\
\text { to solvent }\end{array}$ & & $\begin{array}{l}\text { The stabilization of this mutation is most } \\
\text { likely the result of the optimization of } \\
\text { hydrogen bonding, given that there is no net } \\
\text { increase in the number of hydrogen bonds }\end{array}$ \\
\hline General comments & $\begin{array}{l}\text { The rearrangement of the segment } 302-307 \\
\text { occurs at the expense of exposing more } \\
\text { hydrophobic surface to solvent }\end{array}$ & & $\begin{array}{l}\text { The movement of the main-chain and side- } \\
\text { chain atoms of Thr } 326 \text { optimizes the hydrogen } \\
\text { bonding interactions }\end{array}$ \\
\hline
\end{tabular}


(a)

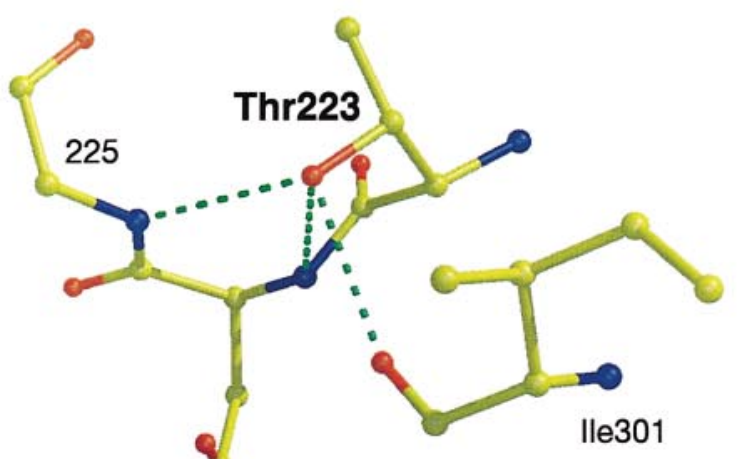

Asp224

(b)

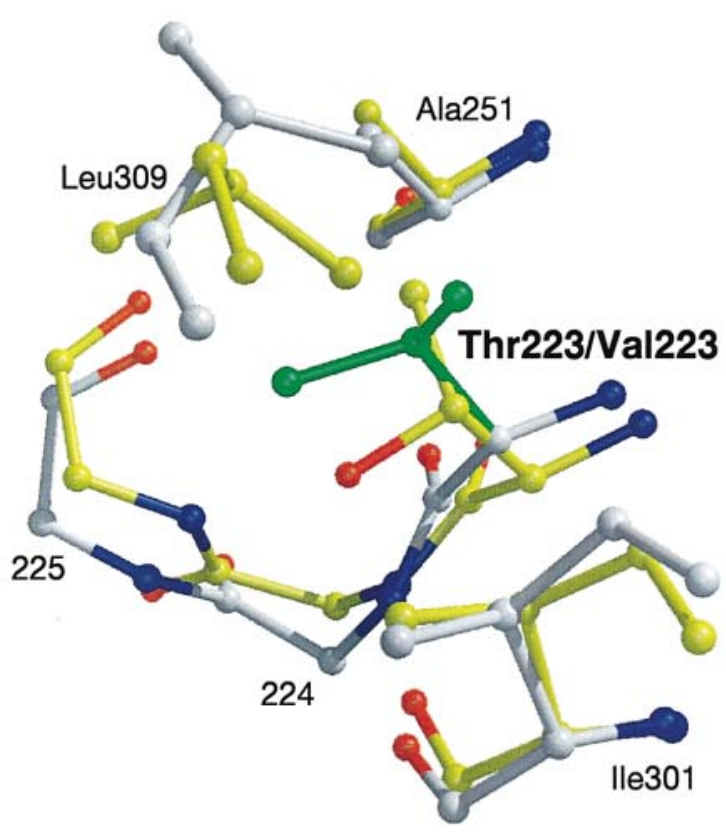

(c)

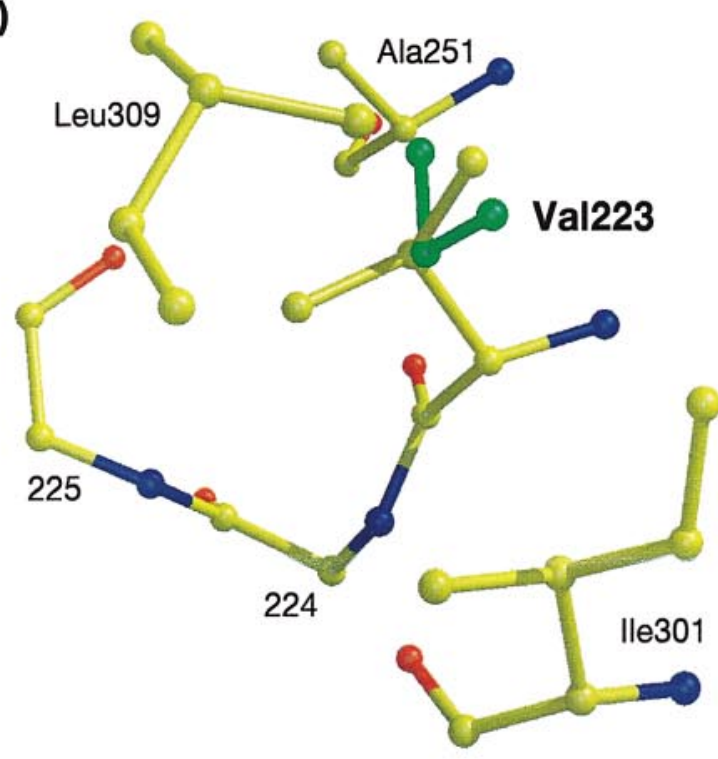

structure. Favourable reorganization is responsible for the increased stability of Ile305 $\rightarrow$ Leu.

Despite the overall similarity of the two mutant structures, which differ only by one residue in sequence, the details of interactions at the corresponding mutation sites are not identical. This structural discrepancy between the two mutants supports the different degree of additivity in stability displayed by M1 and M2.

\section{Engineering protein stability: where to make the stabilizing mutation?}

The effects of a particular mutation on protein stability and structure result from a combination of various forces. Some of them are context-independent, such as side-chain hydrophobicity and conformational entropy. These effects are relatively well characterized. Some are dependent on the structural context and on the ability of surrounding residues to relax in response to mutation. The current difficulty in engineering protein stability lies in identifying positions in a protein that will lead to stabilization when substituted (Sandberg \& Terwilliger, 1991).

Naturally occurring variations are more frequently found at surface positions of proteins, while protein cores evolve relatively slowly (Perutz et al., 1965). It is commonly believed that protein core residues are immutable and generally optimized for energy, while on the contrary, surface residues are variable and hence unimportant for stability. However, our current study shows that both core and surface residues have important contribution to protein stability. In conjunction with other studies (Lim et al., 1994; Axe et al., 1996), it suggests that protein cores are more flexible and more tolerant to substitution than expected and, therefore, optimization of protein cores could result in improved packing and hence increased stability. Moreover, shielding from solvent and close packing in protein cores would result in a larger stabilization of core mutations than surface ones. Local flexibility is likely to be the key factor that allows relatively large structural rearrangements and concomitant stabilization to occur in protein cores as seen in this study and in lambda repressor (Lim et al., 1994), as supported by extensive studies on hydrophobic core mutations (Kellis et al., 1988, 1989; Shortle et al., 1990; Eriksson et al., 1992;

Figure 1. (a) Hydrogen bonds made by the side-chain of Thr223 in the mutant structure M1. Hydrogen bonds are shown as broken lines. (b) Superposition of the structures of M1 (yellow bonds) and M2 (white bonds) at the site of 223. The side-chain of Val223 is shown in green. (c) Two conformations displayed by Val223 in the crystal structure of the apical domain of Thermus thermophilus Cpn60. The second conformation is in green. Drawn with Molscript (Kraulis, 1991) and rendered with Raster3D (Merritt \& Bacon, 1997). 

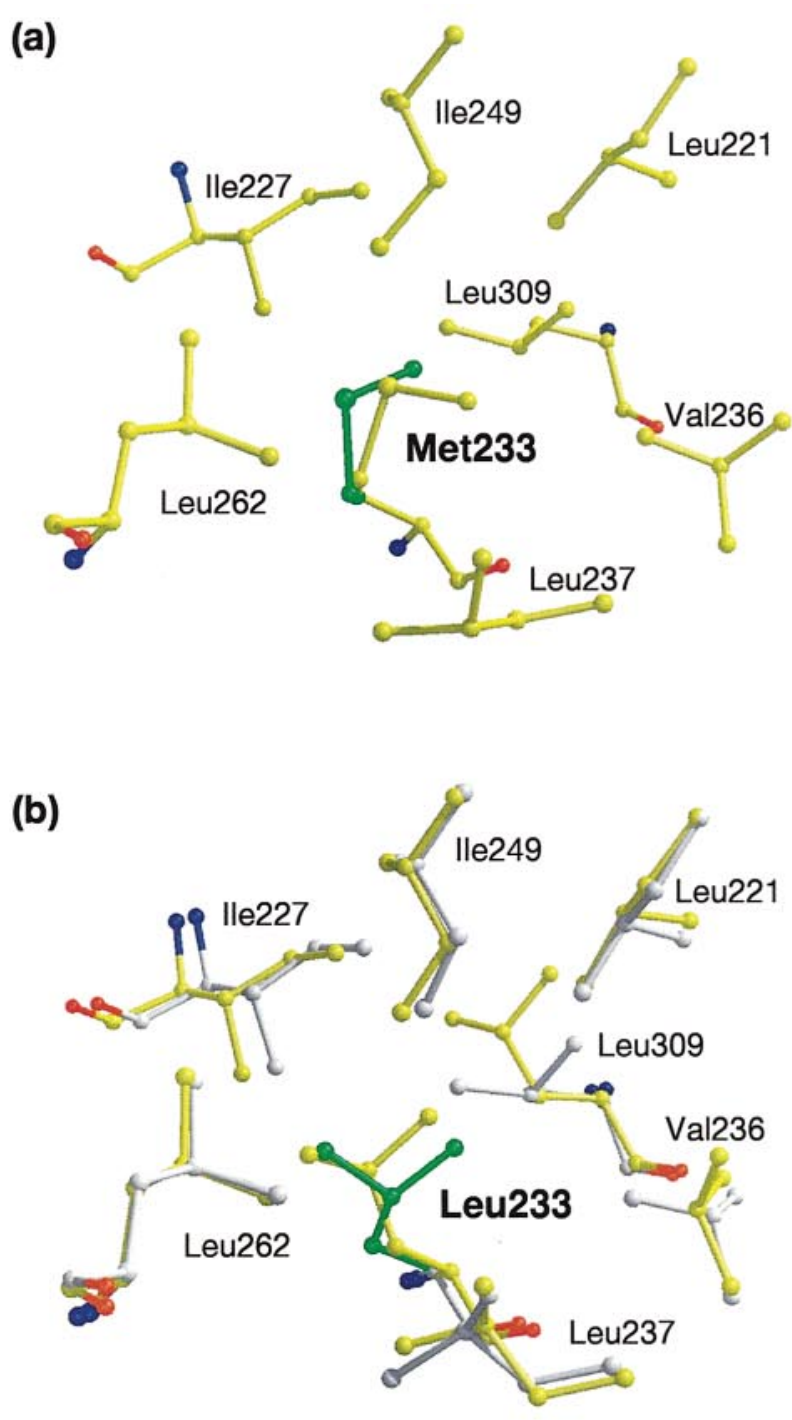

(c)

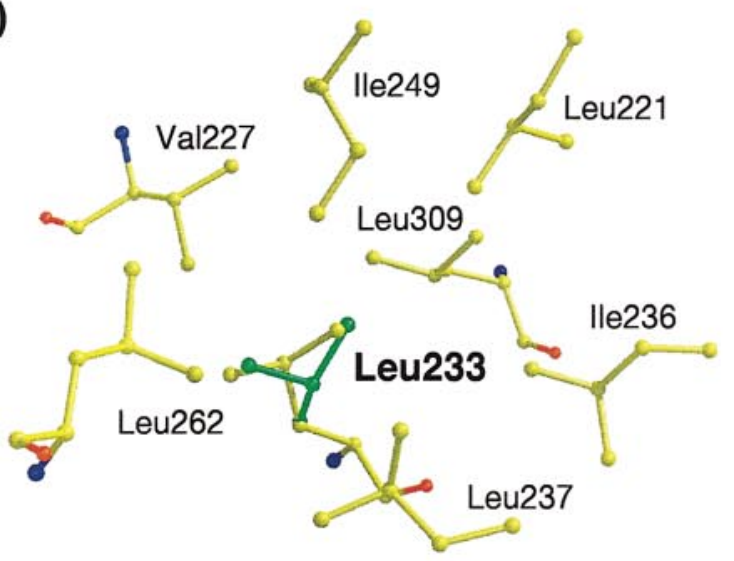

Figure 2. Flexibility at position 233. (a) Two conformations displayed by Met233 in GroEL(191-376). (b) Superposition of the structures of M1 (yellow) and M2 (white) at the site of 233. The side-chain of Leu233 in M2 is in green. (c) Two conformations displayed by
Serrano et al., 1992; Jackson et al., 1993; Takano et al., 1995).

As protein stability is not generally optimized during the course of evolution (Serrano et al., 1993; Schreiber et al., 1994), variations, most frequently at protein surfaces, occur as a result of random drift (Kimura, 1968). Some variations may be stabilizing while others are destabilizing. The overall stability level is maintained within a narrow range of $5-15 \mathrm{kcal} \mathrm{mol}^{-1}$. On the other hand, however, when protein stability is under constant selective pressure, for example for proteins in thermophiles, many small stabilizing variations are accumulated to improve the overall stability (Argos et al., 1979). However, the important contribution of surface residues to protein stability and function (Predki et al., 1996; D.D. Axe \& A.R.F., unpublished data) is heavily masked by their high variability. Sequence comparison of homologous proteins has provided a way to pinpoint the residues that contribute constructively to protein stability and to guide the subsequent engineering of protein stability. Stabilizing mutations identified by this approach are most frequently located at protein surfaces but with a few found in protein cores (Serrano et al., 1993; Nikolova et al., 1998; Wang et al., 1999). Combination of several stabilizing mutations would create dramatically stabilized mutant proteins.

\section{Materials and Methods}

\section{Protein construction, expression and purification}

The plasmid pRSET A (InVitrogen) was used in gene manipulation and protein expression and the proteins GroEL(191-376) M1 and M2 for crystallization. In order to obtain GroEL(191-376) M1 and M2, a silent mutation $(\mathrm{T} \rightarrow \mathrm{C})$ was first introduced within the minichaperone genes at the site of residue 195 in GroEL(191-376) and GroEL(193-345) M1 and M2, to create a unique SacII site. After double digestion of the plasmids by SacII and ClaI, the smaller fragment from either GroEL(193-345) M1 or M2, each of which comprises the desired six mutations, was combined with the larger fragment from GroEL(191376). GroEL(191-376) M1 and M2 with an N-terminal histidine-tag were expressed in Escherichia coli BLR(DE3) and purified in two steps essentially as described (Wang et al., 1999). Pure proteins were buffer-exchanged into pure water and stored at $-70^{\circ} \mathrm{C}$ at a concentration of $22 \mathrm{mg} \mathrm{ml}^{-1}$ for both M1 and M2.

\section{Protein crystallization and data collection}

Crystals of both M1 and M2 were obtained by hanging-drop vapour diffusion (McPherson, 1982), in 0.75$0.90 \mathrm{M}$ sodium potassium tartrate, $50 \mathrm{mM}$ Mes sodium (2-(N-morpholino)ethane-sulfonic acid) ( $\mathrm{pH}$ 6.5). In each

Leu233 in the apical domain of T. thermophilus Cpn60. The second conformations of Met233 in (a) and Leu233 in (c) are in green. Drawn with Molscript (Kraulis, 1991) and rendered with Raster3D (Merritt \& Bacon, 1997). 
(a)

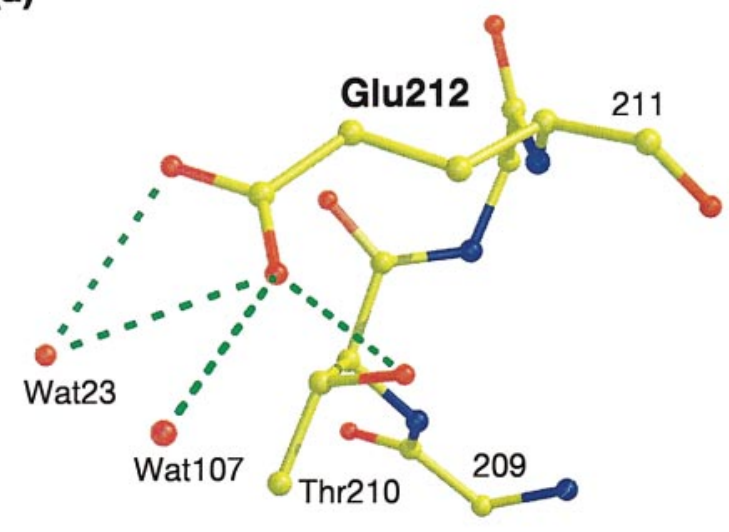

(c)

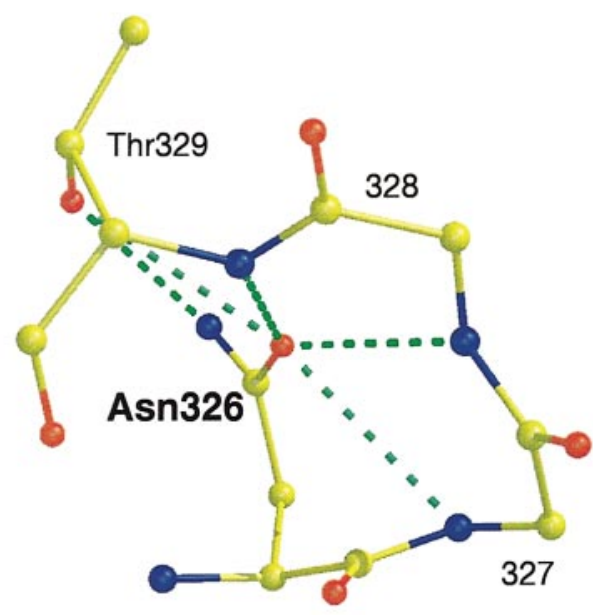

(b)

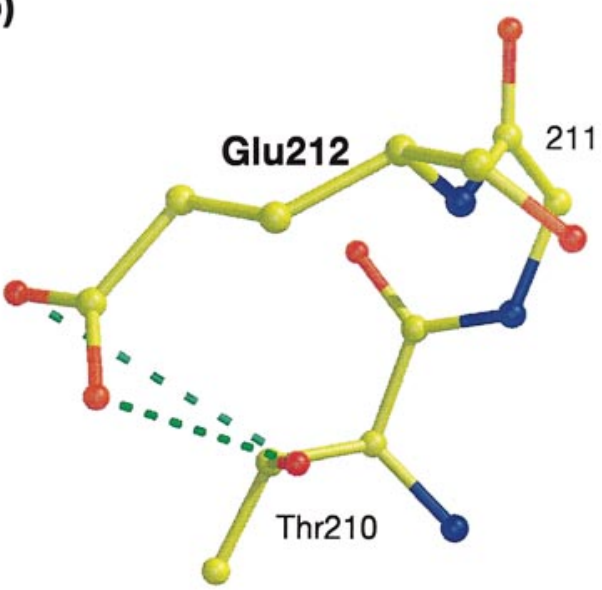

(d)

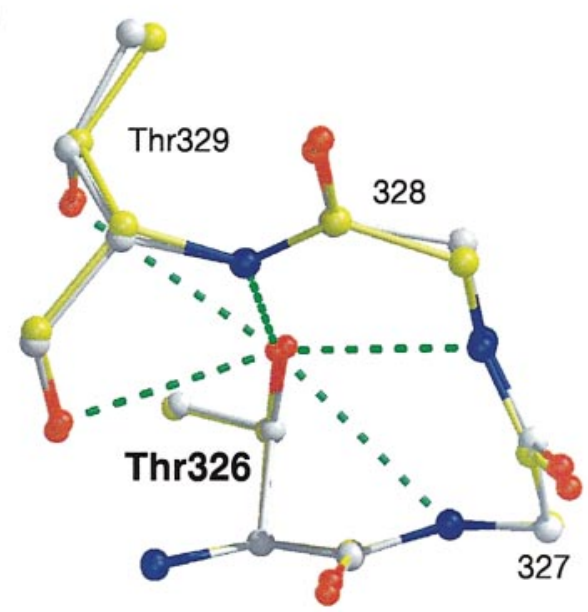

Figure 3. Comparison of hydrogen bonding pattern made by the side-chains of Glu212 in the mutant structures M1 (a) and M2 (b), Asn326 in wild-type structure (c) and Thr326 in M1 (yellow bonds) and M2 (white bonds) (d). Hydrogen bonds are shown as broken lines. Drawn with Molscript (Kraulis, 1991) and rendered with Raster3D (Merritt \& Bacon, 1997).

case, a complete data set to $2.2 \AA$ was collected from a single crystal cooled to $100 \mathrm{~K}$, in the cryoprotectant of the respective mother liquor plus $20 \%$ (v/v) glycerol, using the beamline DW32 at LURE, Paris $(\lambda=0.9630 \AA)$.

\section{Structure determination and analysis}

Data processing, data reduction, electron density manipulation and structural analyses were carried out using CCP4 programs (CCP4, 1994). $5 \%$ of each data set were flagged with free $R$ and used for cross-validation purposes (Brunger, 1992a). AMoRe was used for molecular replacement calculations (Navaza, 1994) using the refined structure of GroEL(191-376) without solvent (Buckle et al., 1997) as a search model. There is one molecule per asymmetric unit in both cases. Structure refinement was initiated with simulated slow cooling using XPLOR (Brunger, 1992b) followed by maximum-likeli- hood using REFMAC (Murshudov et al., 1997). Model building was performed using O (Jones et al., 1991) and PROCHECK (CCP4, 1994) was used to check the stereochemistry of the model.

\section{Acknowledgements}

We thank Dr P.R. Evans at MRC Laboratory of Molecular Biology, Cambridge for providing the PROTIN library that includes the glycerol molecule. A studentship to Q.W. from UK Overseas Research Students Awards, Cambridge Overseas Trust and the Herchel Smith Endowment from Department of Chemistry, University of Cambridge is gratefully acknowledged. 


\section{References}

Argos, P., Rossman, M. G., Grau, U. M., Zuber, H., Frank, G. \& Tratschin, J. D. (1979). Thermal stability and protein structure. Biochemistry, 18, 5698-5703.

Axe, D. D., Foster, N. W. \& Fersht, A. R. (1996). Active barnase variants with completely random hydrophobic cores. Proc. Natl Acad. Sci. USA, 93, 55905594.

Baldwin, E. P., Hajiseyedjavadi, O., Baase, W. A. \& Matthews, B. W. (1993). The role of backbone flexibility in the accommodation of variants that repack the core of T4 lysozyme. Science, 262, 1715-1718.

Brunger, A. T. (1992a). The free $R$ value: a novel statistical quantity for assessing the accuracy of crystal structures. Nature, 355, 472-474.

Brunger, A. T. (1992b). XPLOR Manual, version 3.0, Yale University, New Haven, CT.

Buckle, A. M., Zahn, R. \& Fersht, A. R. (1997). A structural model for GroEL-polypeptide recognition. Proc. Natl Acad. Sci. USA, 94, 3571-3575.

CCP4 (1994). The CCP4 suite: programs for protein crystallography. Acta Crystallog. sect. D, 50, 760-763.

Daopin, S., Alber, T., Baase, W. A., Wozniak, J. A. \& Matthews, B. W. (1991). Structural and thermodynamic analysis of the packing of two alpha-helices in bacteriophage T4 lysozyme. J. Mol. Biol. 221, 647667.

Eriksson, A. E., Baase, W. A., Zhang, X. J., Heinz, D. W., Blaber, M., Baldwin, E. P. \& Matthews, B. W. (1992). Response of a protein structure to cavitycreating mutations and its relation to the hydrophobic effect. Science, 255, 178-183.

Fersht, A. R. (1999). Structure and Mechanism in Protein Science. A Guide to Enzyme Catalysis and Protein Folding, W.H. Freeman and Company, New York.

Fersht, A. R. \& Serrano, L. (1993). Principles of protein stability derived from protein engineering experiments. Curr. Opin. Struct. Biol. 3, 75-83.

Gassner, N. C., Baase, W. A. \& Matthews, B. W. (1996). A test of the "jigsaw puzzle" model for protein folding by multiple methionine substitutions within the core of T4 lysozyme. Proc. Natl Acad. Sci. USA, 93, 12155-12158.

Jackson, S. E., Moracci, M., elMasry, N., Johnson, C. M. \& Fersht, A. R. (1993). Effect of cavity-creating mutations in the hydrophobic core of chymotrypsin inhibitor 2. Biochemistry, 32, 11259-11269.

Jones, T. A., Zou, J. Y., Cowan, S. W. \& Kjeldgaard, M. (1991). Improved methods for building protein models in electron density maps and the location of errors in these models. Acta Crystallog. sect. A, 93, 110-119.

Karpusas, M., Baase, W. A., Matsumura, M. \& Matthews, B. W. (1989). Hydrophobic packing in T4 lysozyme probed by cavity-filling mutants. Proc. Natl Acad. Sci. USA, 86, 8237-8241.

Kellis, J. T., Jr, Nyberg, K., Sali, D. \& Fersht, A. R. (1988). Contribution of hydrophobic interactions to protein stability. Nature, 333, 784-786.

Kellis, J. T., Jr, Nyberg, K. \& Fersht, A. R. (1989). Energetics of complementary side-chain packing in a protein hydrophobic core. Biochemistry, 28, 49144922.

Kimura, M. (1968). Evolutionary rate at the molecular level. Nature, 217, 624-626.

Kraulis, P. J. (1991). Molscript: a program to produce both detailed and schematic plots of protein structure. J. Appl. Crystallog. 24, 946-950.
Lim, W. A., Hodel, A., Sauer, R. T. \& Richards, F. M. (1994). The crystal structure of a mutant protein with altered but improved hydrophobic core packing. Proc. Natl Acad. Sci. USA, 91, 423-427.

Matthews, B. W. (1995). Studies on protein stability with T4 lysozyme. Advan. Protein Chem. 46, 249-278.

McPherson, A. (1982). The Preparation and Analysis of Protein Crystals, John Wiley \& Sons, New York.

Merritt, E. A. \& Bacon, D. J. (1997). Raster3D: photorealistic molecular graphics. Methods Enzymol. 277, 505-524.

Miller, S., Janin, J., Lesk, A. M. \& Chothia, C. (1987). Interior and surface of monomeric proteins. J. Mol. Biol. 196, 641-656.

Munoz, V., Cronet, P., Lopez-Hernandez, E. \& Serrano, L. (1996). Analysis of the effect of local interactions on protein stability. Fold. Des. 1, 167-178.

Murshudov, G. N., Vagin, A. A. \& Dodson, E. J. (1997). Refinement of macromolecular structures by the maximum-likelihood method. Acta Crystallog. sect. $D, 53,240-255$.

Navaza, J. (1994). AMoRe: an automated package for molecular replacement. Acta Crystallog. sect. A, 50, 157-163.

Nikolova, P. V., Henckel, J., Lane, D. P. \& Fersht, A. R. (1998). Semirational design of active tumor suppressor p53 DNA binding domain with enhanced stability. Proc. Natl Acad. Sci. USA, 95, 14675-14680.

Perutz, M. F., Kendrew, J. C. \& Watson, H. C. (1965). Structure and function of haemoglobin II. Some relations between polypeptide chain configuration and amino acid sequence. J. Mol. Biol. 13, 669-678.

Predki, P. F., Agarwal, V., Brunger, A. T. \& Regan, L. (1996). Amino acid substitutions in a surface turn modulate protein stability. Nature Struct. Biol. 3, 54-58.

Regan, L., Serrano, L., Sali, A., Horovitz, A. \& Wilson, C. (1996). Paper alert. Fold. Des. 1, R115-119.

Russell, R. J. \& Taylor, G. L. (1995). Engineering thermostability: lessons from thermophilic proteins. Curr. Opin. Biotechnol. 6, 370-374.

Sandberg, W. S. \& Terwilliger, T. C. (1991). Repacking protein interiors. Trends Biotechnol. 9, 59-63.

Schreiber, G., Buckle, A. M. \& Fersht, A. R. (1994). Stability and function: two constraints in the evolution of barstar and other proteins. Structure, 2, 945-951.

Serrano, L., Kellis, J. T., Jr, Cann, P., Matouschek, A. \& Fersht, A. R. (1992). The folding of an enzyme. II. Substructure of barnase and the contribution of different interactions to protein stability. J. Mol. Biol. 224, 783-804.

Serrano, L., Day, A. G. \& Fersht, A. R. (1993). Step-wise mutation of barnase to binase. A procedure for engineering increased stability of proteins and an experimental analysis of the evolution of protein stability. J. Mol. Biol. 233, 305-312.

Shortle, D., Stites, W. E. \& Meeker, A. K. (1990). Contributions of the large hydrophobic amino acids to the stability of staphylococcal nuclease. Biochemistry, 29, 8033-8041.

Takano, K., Ogasahara, K., Kaneda, H., Yamagata, Y., Fujii, S., Kanaya, E., Kikuchi, M., Oobatake, M. \& Yutani, K. (1995). Contribution of hydrophobic residues to the stability of human lysozyme: calorimetric studies and X-ray structural analysis of the five isoleucine to valine mutants. J. Mol. Biol. 254, 62-76. 
Terwilliger, T. C. (1995). Engineering the stability and function of gene V protein. Advan. Protein Chem. 46, 177-215.

Walsh, M. A., Dementieva, I., Evans, G., Sanishvili, R. \& Joachimiak, A. (1999). Taking MAD to the extreme: ultrafast protein structure determination. Acta Crystallog. sect. D, 55, 11681173.

Wang, Q., Buckle, A. M., Foster, N. W., Johnson, C. M. \& Fersht, A. R. (1999). Design of highly stable functional GroEL minichaperones. Protein Sci. 8, 21862193.

Edited by R. Huber

(Received 12 November 1999; received in revised form 21 March 2000; accepted 27 March 2000) 